\title{
The requirement and implications of evidence-based restoration schemes in the United Kingdom
}

\author{
R.N. Humphries Celtic Energy Ltd, UK
}

\begin{abstract}
Over the past two decades, 'evidence-based' decision making has become a universally established process for those developing and evaluating government policy and regulation. Although the process originated in the delivery of health care, it is has been widely applied in the UK to include natural resource management and more recently extended to the delivery of mine closure schemes.

This has resulted in a fundamental, but largely unsaid, change in the approach of planning authorities and regulators to the development control of mine restoration schemes in the UK. Traditionally, this took the form of a report describing the nature and characteristics of the restored site on the completion of the restoration works. Only at this late point in the delivery of the restoration were schemes judged as being fit or unfit for purpose. In contrast, the evidence-based approach is applied early in the planning process and before consent is granted, and is concerned with the certainty (likelihood) that schemes will be delivered. This requires the applicant to provide verified example Case or Pilot Studies of successful schemes that have been achieved in similar situations and by similar methods.

This is particularly the case where UK Priority Habitats are proffered as replacements for losses or gains as a result of proposed mining schemes. Given this, the industry should expect to be challenged by both planning authorities and regulators. This paper discusses the implications for the mining industry and the need for a national repository of Case and Pilot studies and suggests the type of data to be collected to enable independent and objective review.
\end{abstract}

\section{Introduction}

This paper is about the requirement for an evidence base to support the certainty of delivery of restoration proposals for nature conservation in mineral extraction schemes in the UK and the demands it is likely to make on the mining industry. The benefit of the approach for nature conservation management of existing resources has been advocated (Pullin and Knight, 2009) and is now fully recognised at government level (Parliamentary Office of Science \& Technology, 2011). Although attention has only recently been drawn to the concept and use of an evidence-based approach in mine closure planning (Ntshotsho et al., 2011; Humphries, 2012) as a methodology for evaluating and recommending science-based practice, it is not new to the restoration of mineral workings in the UK (Humphries et al., 1984; Street, 1985). The quest for evidence for better restoration was the basis for government- and industry-funded research in the late 1980s and the 1990s. The former culminated in government guidance, such as 'Mineral Planning Guidance 7: Reclamation of Mineral Workings' (Department of the Environment, 1996), and the latter was manifest in the funding of dedicated research units at UK universities (British Coal, 1988).

The consenting of mineral extraction and mine closure planning in the UK is governed by national legislative and policy frameworks and by local development plans (National Assembly for Wales, 2001; Regional Planning \& Transportation Division, 2001; Scottish Government Directorate for the Built Environment, 2009; Communities and Local Government, 2012). These have progressively evolved over the past 70 years from a weighting favouring resource protection and exploitation to one ensuring environmental and socioeconomic protection. A key facet of the environmental protection measures is for restoration schemes to deliver on their aims and to be fit for purpose. This aspect of mineral development planning and regulation has been subject to a significant change in approach and expectations over the past 20 years from the 
simple acceptance of largely promissory and 'aspiration-led' restoration proposals devised late in the mining programme (with the inherent uncertainty of delivery that this had) to one where evidence of the certainty of delivery is demanded upfront at the planning consultation and decision making stages.

The current evidence-led approach to policy and decision making in the UK can be traced back to the late 1990s, when the newly formed Labour government adopted it as the basis for policy making and abandoned the previous traditional ideological-precedent-based approach (Cabinet Office, 1999a, 1999b). The approach has its origin in the medical profession, where it has become established in the support of clinical decisions and health treatments (Sackett, 1996; Gray, 1997). The underpinning principle is that the evidence-based approach is a scientifically based process (i.e., systematic, factual and reasoned). It is now embodied in the structure of governmental institutions in the UK and elsewhere and in their approach when implementing policy and decision making (Davies, 2004; Banks, 2009). In the UK, the process is now fully embedded in the protection and enhancement of natural resources and in developments such as mineral extraction.

\section{Outputs and outcomes}

Those proffering an evidence-based approach have largely focused their attention on the processes involved (Humphries et al., 1984; Humphries, 2000; Pullin and Knight, 2009; Ntshotsho et al., 2011; Guldemond et al., 2012). In considering approaches to restoration, Doick (2010) importantly draws our attention to the relation of the process element in the delivery of the aims as the tangible outcomes. In this context there is clear differentiation between outputs and outcomes, where outputs are part of the process. This needs to be understood and is explored further below.

In considering the evidence-based approach of Pullin and Knight (2009), their outputs of the process take the form of systematic reviews, which if applied result in improved outcomes. In aligning their proposed evidence-based approach to conservation and environmental management to the Cochrane Collaboration model (Cochrane, 1972), they advocate the outputs are lodged as a library of readily accessible reviews.

Davies (2004), in taking a wider view of the possible form of evidence bases used by the UK government, gives some helpful oversight into the form of outputs relevant to the restoration of mine closure sites. In doing so, he makes it clear that each of four generic types of outputs have their place and limitations. He is doubtful about the value of expert opinion as evidence, owing to the inherent risk of their 'narrow' views and 'out-of-date knowledge'. He considered that research was best suited to understanding the narrow aspects of process and mechanisms, whereas critical reviews (if well done) provided wider balanced views. However, Davies favoured Case and Pilot Studies as the most useful outputs, as these were more likely to demonstrate attainment of the proposed outcome in practice (this being the purpose of adopting an evidence-based approach). He helpfully ranks the value of the four approaches in descending order of value as evidence: Case Studies and Pilot Studies (the highest value), Critical Reviews, Research and Expert Opinion (the lowest value).

Case Studies as outputs, where applicable, would serve to establish a track record in delivery of functioning land uses, resources, habitats and species, etc. and be based on factual and science-based information. Importantly, these are at the operational and site scale and are delivered using available equipment and techniques. Pilot Schemes are also at an operational scale, but not necessarily at the site scale. They are not the same as research plots in scale and method of implementation. They are applicable where there is an absence of evidence or it is weak or incomplete. Typically they would be employed for innovative approaches or new techniques or unusual habitats, etc.

\section{Evidence-based biodiversity restoration}

The UK is fully signed up to the global Convention on Biological Diversity (CBD) and its objectives to conserve and enhance the UK's biodiversity capital through planning controls and cultural change in our everyday lives and activities (Joint Nature Conservation Committee, 2012). The impact of the CBD in the UK 
has been profound and has spawned change in approaches to environmental policy from single-item agenda (e.g., water) to a multi-topic agenda (e.g., water-biodiversity-climate change) under the aegis of ecosystem services (UK National Ecosystem Assessment, 2011). National and local policies, as planning and decision tools, integrating biodiversity with natural resource exploitation, economics and society needs in the UK, are programmed to be in place by 2014 and effective from 2020.

Since the mid-1990s the UK has had in place an action plan to conserve and enhance its biodiversity assets (Joint Nature Conservation Committee, 2013a). In doing so it has identified those habitats that are considered to be key elements in its contribution to the conservation of UK and global biodiversity. In the UK these are referred to as Priority Habitats and are synonymous with the terminology used globally for important habitat assets. Currently there are some 66 designated terrestrial and marine Priority Habitats in the UK (Joint Nature Conservation Committee, 2013a).

In historical terms, the restoration of Priority Habitats in association with mineral extraction sites is relatively new, and whilst successful examples (particularly wetland habitat) predate the publication of the UK's Biodiversity Action Plan (BAP) in the 1990s, it is not until the last decade and a half that there has been a focus on them specifically. The focus was heightened with the Natural Environment and Rural Communities Act 2006 (UK Government, 2006) which imposed a duty on local governments to conserve and enhance biodiversity within their jurisdiction and to report on the losses and gains of BAP habitats and species to the UK government. In this context, mineral workings in particular were seen quite early on as an opportunity for offsetting losses elsewhere or as a source of net gains (Bennett, 2007).

Best available practice for the successful agricultural and forestry restoration of mineral workings in the UK is well documented, and the underlying scientific principles are established and understood following some 30 years of research and development work (e.g., Department of the Environment, 1996; Moffatt and McNeill, 1994; Ministry of Agriculture, Fisheries and Food, 2000). As a result, over the past 20 or more years many examples of good agricultural and forestry restoration have been achieved and, importantly, have become well known to the planning authorities through reclamation-based networks and seminars (e.g., British Land Reclamation Society, Local Authorities Association, and Royal Town Planning Institute). Hence, proposed restoration schemes incorporating the key elements for agricultural and forestry restoration are now rarely challenged. However, this should not be assumed to be the case for schemes that are concerned with the establishment of 'semi-natural' habitats and vegetation of high conservation value, such as those categorised as Priority Habitats.

In the UK, many mineral extraction sites are juxtaposed with or contain elements of Priority Habitats. As mineral extraction can only occur where the mineral exists and where extraction results in the loss in Priority Habitat, conservation regulators and planning authorities will require it to be replaced on site restoration. In other situations Priority Habitat may be offered as an inducement to consent to a particular site development. In both cases the certainty of restoration will be of concern to ensure compliance with UK biodiversity policies of 'no net loss' and undertakings to 'restore and enhance' arising from the Convention on Biological Diversity (Convention on Biological Diversity, 2013).

This raises the issue of the degree of confidence that such planning decisions should give to such proposals. To have confidence, there needs to be both a thorough scientific understanding of the structural elements and functions supporting the Priority Habitats and, importantly, verified examples of the habitats created in similar circumstances elsewhere. The current situation is that both planning authorities and regulators are demanding evidence in advance of granting planning consent that proposed Priority Habitats can be created.

\section{$4 \quad$ Outputs for priority habitats}

As set out above, the type of output should be examples of restoration achieved in practice and presented either as a Case Study (where the techniques and situation were not deemed to be experimental) or as a Pilot Study (where the technique, situation or habitat type had no known precedent or previous success). 
Clearly, in the case of Priority Habitats, the evidence is to be manifest in the form that relates to and can verify the required outcome.

Sutherland et al. (2004) suggest a generalised but somewhat 'loose' content for an evidence base for nature conservation management. In the context of this discussion and the restoration of Priority Habitats on mineral sites, the evidence base and outputs need to be more specific and consistent to enable a rigorous and object approach and interrogation of the collected data. Intuitively, it would be expected to take the form of the representative type of the aspired habitat/vegetation. In simple terms, the target vegetation would be defined using a recognised classification system and methodology. In the UK this is likely to be the National Vegetation Classification (NVC) System (Joint Nature Conservation Committee, 2013b), to which the examples being verified must ascribe. Adopting this as the outcome (i.e., the objective of the proposed evidence-based approach to restoring and creating Priority Habitats) on mine closure sites, the establishment of the target NVC habitat-vegetation type would either qualify or not qualify, according to species composition and frequency of occurrence. This approach has been used and advocated in the assessment of the achievement of Priority Habitat types of grassland and wetland vegetation restoration on mined land (Humphries and Benyon, 1999; Humphries and Meade, 2007).

The core evidence required for each Case Study would consist of the outputs from surveys and assessments using the standard methodology (Rodwell, 2006) to determine the main and any variant NVC types within the vegetation being determined. These core data should consist of the likely NVC output (which may be supplemented by programmes such as MATCH (Malloch, 1990), TABLEFIT (Hill, 1991) or MAVIS (Centre for Ecology \& Hydrology (2013)) supported by the requisite constancy tables, and also information such as plans and photographs, date and conditions at time of survey, the surveyors and assessors and the source and availability of the raw and core data. In some cases there may be only single point surveys, whilst for others there may be a sequence of surveys over a number of years. Where there are published reports and papers relating to the Case Study, these should be listed. Together, this information should enable an independent review. Unless the outputs are capable of independent review, they will have little scientific currency and will be open to doubt by decision makers and regulators.

The core evidence outputs need to be supplemented with physical details of the site (such as an identification name, location (BSBI Vice-County; OS grid reference), altitude, climatic data, landform) and background information - age of scheme, method of restoration/creation (e.g., natural regeneration, planted, seeded, translocation), soil materials (natural soils [top/sub-soil], soil forming materials, overburden, other [to be defined]), land use (to include whether operational or restored land, agricultural, amenity, nature conservation etc.) and any other relevant information. The supplementary details would include who were the delivery and land-owning organisations and the local government authority and other stakeholder bodies, where relevant.

For there to be collective benefit from the evidence outputs set out above for the reclamation and creation of Priority Habitats on mine sites, there needs to be the collation of the outcome and outputs of schemes. This would provide a track record and evidence for the attainment of NVC types with information about effective techniques and circumstances that could be used to guide schemes elsewhere. This raises the need for a central repository and is discussed further below.

Whilst the evidence-based outputs are derived from a variety of individual surveyors and recorders, there is a need (beyond the simple verification of the evidence) for independent and informed oversight and for a means of objectively assessing the success of Case and Pilot Studies. Obviously the attainment of a recognisable NVC vegetation type and in particular the target type is a key qualifying attribute, but not in isolation of others.

An important aspect of assessing Priority Habitat restoration is the attainment of an appropriate degree of maturation and sustainability. This is a matter of time, which varies according to habitat/vegetation type. Here Common Standards Monitoring criteria (Joint Nature Conservation Committee, 2013c) could be applied as a means of adjudication. For example, in applying the core structural requirements for functioning Priority Habitats ecosystems, this could be about 15 years for grassland, 30-50 years for dwarf 
shrub communities and 150 years or longer for woodland (Humphries, 2013). The notion of minimum size (area) of such habitats is recognised as being important for their integrity. Therefore, the assessments need to be augmented with a minimum threshold size for the target habitats. These could be based on the qualifying area for County Wildlife Sites, contributing areas for Biodiversity Action Plans or qualifying areas for Common Standards Monitoring. As a result, it would be possible to categorise the Case and Pilot Studies as 'Achieving' or 'Not Achieving' the target NVC type, or as 'Candidate' schemes (in the case of developing ecosystems) on national, regional or local levels.

A product of the compilation of the Case and Pilot Study data would be a listing of NVC types that could be referred to in resource protection and mine reclamation planning. For commonly occurring Priority Habitats, it is anticipated there would be a substantial list of examples, whereas for rarer Habitats there would be few if any to consult. The assessment proposed above would provide science-based evidence as to which Priority Habitats were being successfully restored versus those not being successfully restored/created, or those where evidence was awaited. The latter may be due to a range of inherent factors affecting restorability, the time scale involved or simply the unavailability as yet of appropriate techniques. Where such issues are of resource protection importance or economic importance, the compiled evidence could be used to guide future research and development studies.

\section{$5 \quad$ A national repository of outputs and outcomes}

In adopting an evidence-based approach in the medical and social sectors, it was quickly apparent that there was a need for an accessible repository if any benefits were to be realised in practice. This resulted in the setting up of the Cochrane Collaboration (Cochrane, 1972) for medical-related policies and practices, and more recently the Campbell Collaboration (Campbell Collaboration, 2013) for socio-economic related issues for society. On a less formal scale, Sutherland et al. (2004) suggest the use of newsletters and websites by organisations active in nature conservation as a means of influencing practice.

At present there is no central data holding body for the outputs and outcomes of evidence-based restoration schemes in the UK for either mineral sites or other schemes and initiatives. The merit of such a body had been advocated more than a decade ago (Humphries, 2000). With the recent formal adoption of an evidence-based approach by government and regulators, this has made it an imperative if the full benefit of restoration knowledge is to be realised.

It is the UK government's stated policy to encourage the pooling and sharing of environmental information between industry, developers, regulators and planning authorities. Here, Defra (2013) has recently made its Biodiversity Action Reporting System available to other organisations besides those receiving government funding for agri-environmental offset schemes. However, it appears at present that this spatially related database is essentially a tool for recording the number and location of schemes, as well as pending aspirational targets for increasing biodiversity assets. It does not provide specific detail of schemes nor any means of evaluation to enable it to be used as an evidence base. Another database, the Integrated Biodiversity Assessment Tool (World Conservation Monitoring Centre, 2013), is similar: whilst providing spatial biodiversity conservation information on a global scale and the implications for development, it does not provide specific or technical data to enable evaluations (as described above) to be made.

As can be seen from their corporate websites, the larger UK mineral companies record their achievements and maintain their own records, and several use the Case Study approach for selected sites. Although their achievements are reported through company and third party media, and are often submitted for peer review for institutional awards, the underlying data collected are not readily made available to others for wider compilation and scrutiny. Given that each company has embarked on its own recording and reporting initiative, it is certain there is no cross-industry standard, thereby making it difficult to establish common standards. Many reports are for 'headline' species and their supporting habitat types in general, such as bittern and reed beds. Similarly, the planning authorities involved do not keep records other than specialist progress reports commissioned by the mineral operator (these are most likely to have been a result of a planning consent condition) for a particular development. Whilst these should be made available on 
request from the individual authorities, it is likely to take a lot of effort to locate and obtain them. Again, the form of data and the ability to interpret them in a consistent and convenient manner are likely to be limited.

What is needed is an institution that has the capability of collating and categorising data and of providing objective, science-based reviews of data held and independent and informed assessments on request, as well as, importantly, a long track record of stewardship of nationally important archives.

\section{Implications for the minerals industry}

Ntshotsho et al. (2011) note that the mining industry, funders, decision makers and regulators in South Africa have been particularly slow in adopting an evidence-based mine closure programmes, and what is needed is a 'mind-shift' in awareness. In the UK the situation is a little different, as the business model of decision makers and regulators is now strictly evidence-based, and it is the minerals industry that is left to catch up in its thinking, understanding and response (Humphries, 2012).

Industry will be expected to collect the evidence needed to justify the certainty of delivery of its restoration proposals, and this will be evidence-based proven outcomes. In this respect the mining industry will have to be proactive in its approach. Given the inherent lag time in the maturation of restoration schemes, in particular those involving natural habitats and vegetation such as the Priority Habitats, the minerals industry needs to set up research and monitoring programmes for the evidence-based Case and Pilot Study outputs well in advance of its proposals or have a means of 'data-mining' existing examples. Here, a centralised and accredited body would come into its own. As already mentioned, in the UK, individual mineral companies for some time have been recording and reporting on their biodiversity initiatives. However, the science-based evidence, unless published in peer-reviewed journals or used in planning appeals at public inquiries, remains in the stewardship of the commissioning company and is not generally available to other organisations. Collectively, these data may well provide sufficient evidence for the restoration or creation of several UK Priority Habitats, should they be made available and scrutinised as suggested. This is strongly recommended to the industry, as it is believed this will strengthen its case for the sustainable exploitation of mineral resources that might be currently unavailable. The consequence of the minerals industry not pursuing such an initiative may well be that Priority Habitat-focused restoration may not be accepted as mitigation for proposed mineral workings, and planning consents may be denied.

\section{References}

Banks, G. (2009) Challenges of Evidence-Based Policy-Making, Commonwealth Government of Australia, Brisbane, viewed 27 April 2013, http://www.pc.gov.au/_data/assets/pdf_file/0003/85836/cs20090204.pdf.

Bennett, N. (2007) A partnership approach - The role and work of the National Minerals and Nature Conservation Forum, in Mineral Extraction and Wetland Creation, R. Meade and N. Humphries (eds), Natural England, Peterborough, pp. 29-30.

British Coal (1988) A Seminar on Land Reclamation, British Coal Opencast Executive, Eastwood.

Cabinet Office (1999a) White Paper: Modernising Government, Her Majesty's Government, London.

Cabinet Office (1999b) Professional Policy-Making for the Twenty First Century, Her Majesty's Government, London.

Campbell Collaboration (2013) http://www.campbellcollaboration.org.

Centre for Ecology \& Hydrology (2013) MAVIS, Lancaster, UK, http://www.ceh.ac.uk/.

Cochrane, A.L. (1972) Effectiveness and Efficiency: Random Reflections on the Health Services, Nuffield Provincial Hospitals Trust, London.

Communities and Local Government (2012) National Planning Policy Framework, London, UK, viewed 27 April 2013, http://www.westminster.gov.uk/services/environment/planning/planning-policy/nppf/.

Convention on Biological Diversity (2013) The Convention on Biological Diversity, viewed 27 April 2013, http://www.cbd.int/convention.

Davies, P. (2004) Is Evidence-Based Government Possible? The Jerry Lee Lecture, 4th Annual Campbell Collaboration Colloquium. Washington D.C.

Defra (2013) Biodiversity Action Reporting System (BARS2), viewed 27 April 2013, http://ukbars.defra.gov.uk.

Department of the Environment (1996) Mineral Planning Guidance 7: Reclamation of Mineral Workings, HMSO, London, UK, viewed 27 April 2013,

http://www.planningportal.gov.uk/planning/planningpolicyandlegislation/previousenglishpolicy/mmgmpsmmg/mpg7. 
Doick, K.J. (2010) Learning lessons in monitoring brownfield land regeneration to green-space through logic-modelling, in Restoration and Recovery: Regenerating Land and Communities, H.R. Fox and H.M. Moore (eds), Whittles Publishing, Dunbeath, pp. 16-26.

Gray, J.A.M. (1997) Evidence-Based Healthcare: How to Make Health Policy and Management Decisions, Churchill Livingstone, New York.

Guldermond, R.A.R., Grainger, M.J. and Trimble, M.J. (2012) Where is the evidence for assessing evidence-based restoration? Comments on Ntshotsho et al. (2010), Restoration Ecology, Vol. 20(1), pp. 7-9.

Hill, M.O. (1991) TABLEFIT Software, Centre for Ecology and Hydrology, Monks Wood, viewed 27 April 2013, http://www.ceh.ac.uk/products/software/tablefit/download.asp.

Humphries, R.N. (2000) An evaluative methodology for reclamation achievement \& techniques, in Proceedings of the 17th Annual National Conference of the American Society for Surface Mining and Reclamation, W.L. Daniels and S.G. Richardson (eds),Tampa, Florida, USA, pp. 345-352.

Humphries, R.N. (2012) The emerging requirement for an evidence based certainty for the delivery of restoration schemes in mineral planning applications in the UK, in Proceedings Annual National Meeting of the American Society of Mining and Reclamation: Sustainable Reclamation, R.I. Barnhisel (editor), Tupelo, Mississippi, USA, pp. 286-303.

Humphries, R.N. (2013) Is the definition of scale the key to our understanding and delivery of the components of structure, diversity and function in the restoration of ecosystems? Presented at 2013 National Meeting of the American Society of Mining and Reclamation, Laramie, Wyoming, USA, $24 \mathrm{p}$.

Humphries, R.N. and Benyon, P.R. (1999) Standard criteria and methods to assess the reclamation of native vegetation on mined land, in Proceedings of 16th Annual National Conference of the American Society of Surface Mining and Reclamation, S.A. Bengson and D.M. Bland (eds), Scottsdale, Arizona, USA, pp. 72-80.

Humphries, N. and Meade, R. (2007) Design and reporting criteria for reed bed and fen restoration in mineral workings - Scope and opportunities, in Mineral Extraction and Wetland Creation, R. Meade and N. Humphries (eds), Natural England, Peterborough, pp. 12-28.

Humphries, R.N., Rowell, T.A. and Leverton, R.E. (1984) Evaluation of techniques for the reclamation of tips and lagoons, in Symposium on the Reclamation, Treatment and Utilisation of Coal Mining Wastes, A.K.M. Rainbow (ed), National Coal Board, London, pp. 23.1-23.9.

Joint Nature Conservation Committee (2012) UK Post-2010 Biodiversity Framework, Defra, London.

Joint Nature Conservation Committee (2013a) Joint Nature Conservation Committee, viewed 27 April 2013, http://jncc.defra.gov.uk.

Joint Nature Conservation Committee (2013b) National Vegetation Classification, viewed 27 April 2013, http://jncc.defra.gov.uk/page-4259.

Joint Nature Conservation Committee (2013c) Common Standards Monitoring, viewed 28 April 2013, http://jncc.defra.gov.uk/default.aspx?page=2217.

Malloch, A.J.C. (1990) MATCH, Unit of Vegetation Science, University of Lancaster, Lancaster LA1 4YQ. 177, UK.

Ministry of Agriculture, Fisheries and Food (2000) Good Practice Guide for Handling Soils, viewed 27 April 2013, http://webarchive.nationalarchives.gov.uk/20090306103114/http:/www.defra.gov.uk/farm/environment/landuse/soilguid/index.htm.

Moffatt, A. and McNeill, J. (1994) Bulletin 110: Reclaiming Disturbed Land for Forestry, HMSO, London, UK.

National Assembly for Wales (2001) Mineral Planning Policy Wales, Cardiff, UK.

Ntshotsho, P., Reyers, B. and Esler, K.J. (2011) Assessing the evidence base for restoration in South Africa, Restoration Ecology, Vol. 19(5), pp. 578-586.

Parliamentary Office of Science \& Technology (2011) POST Note PN 379: Evidence-based Conservation, House of Parliament, London.

Pullin, A.S. and Knight, T.M. (2009) Doing more good than harm - Building an evidence-base for conservation and environmental management, Biological Conservation, Vol. 142, pp. 931-934.

Regional Planning \& Transportation Division (2001) Shaping Our Future, Northern Ireland Department of the Environment, Belfast. Rodwell, J.S. (2006) National Vegetation Classification: User's Hand Book, Joint Nature Conservation Committee, Peterborough.

Sackett, D. (1996) Evidence-based medicine - What it is and what it isn't, British Medical Journal, Vol. 312, pp. 71-72.

Scottish Government Directorate for the Built Environment (2009) National Planning Framework for Scotland, Edinburgh.

Street, E.A. (1985) Evaluation procedures for restored land, Environmental Geochemistry and Health, Vol. 7(2), pp. 56-63.

Sutherland, W.J., Pullin, A.S., Dolman, P.M. and Knight, T.M. (2004) The need for evidence-based conservation, Trends in Ecology and Evolution, Vol. 19(6), pp. 305-308.

UK Government (2006) Natural Environment and Rural Communities Act, viewed 28 April 2013, http://www.legislation.gov.uk/ukpga/2006.

UK National Ecosystem Assessment (2011) The UK National Ecosystem Assessment: Synthesis of the key findings, UNEP-WCMC, Cambridge.

World Conservation Monitoring Centre (2013) Integrated Biodiversity Assessment Tool, United Nations Environment Programme, viewed 27 April 2013, http://www.unep-wcmc.org/ibat_512.html. 
in the United Kingdom 